\title{
Three Types of Early Transient Potassium Currents in Aplysia Neurons
}

\author{
Yasuo Furukawa, ${ }^{1}$ Eric R. Kandel, ${ }^{1}$ and Paul Pfaffinger ${ }^{2}$ \\ Howard Hughes Medical Institute and Center for Neurobiology and Behavior, College of Physicians and Surgeons of \\ Columbia University, New York, New York 10032 and 2Division of Neuroscience, Baylor College of Medicine, Houston, \\ Texas 77030
}

In an attempt to categorize the various early transient $K^{+}$ currents (A-type $\mathrm{K}^{+}$currents) present in mature neurons, we have explored these currents in the identified neurons in the abdominal ganglion of the mollusk, Aplysia californica. Three distinct types of A-type $K^{+}$currents $\left(I_{\text {Atant }}, I_{\text {Adlow }}\right.$ and $\left.I_{\text {Adepol }}\right)$ were found. The activation and the steady-state inactivation properties of two of these currents, $I_{\text {Alast }}$ and $I_{\text {Aslow }}$ were similar to conventional A-type $K^{+}$currents. By contrast, those of the third current, $I_{\text {Adopol, }}$, were shifted to more depolarized potentials. Whereas the decay time constants of $I_{\text {Atast }}$ were voltage dependent, those of $I_{A \text { alow }}$ and $I_{\text {Adepol }}$ were almost voltage independent. The recovery from inactivation of $I_{\text {Atan }}$ and $I_{\text {Anlow }}$ was much faster than that of $I_{\text {Adepol }}$ In addition, $I_{\text {Adepol }}$ was more sensitive to 4-aminopyridine (4-AP) than other currents and was almost completely blocked by $1 \mathrm{~mm}$ 4-AP. All the currents were depressed by forskolin or 1,9-dideoxyforskolin, but not by cAMP analogs. None of these currents were blocked by external tetraethylammonium $(50 \mathrm{~mm})$. These results indicate that there are at least three subtypes of A-type $\mathrm{K}^{+}$currents in the Aplysia CNS. Of these, two currents, $I_{\text {Ataut }}$ and $I_{\text {Aslow, }}$ are conventional A-type $K^{+}$currents, whereas the third current, $I_{\text {Adepol}}$, is a novel early transient $K^{+}$ current.

The early transient $\mathrm{K}^{+}$channels (A-type $\mathrm{K}^{+}$channels) are voltage dependent ion channels that are found in a variety of invertebrate and vertebrate nerve and muscle cells (for review, see Rogawski, 1985; Rudy, 1988). Typically, A-type $\mathrm{K}^{+}$channels are inactivated at the resting membrane potential but activate at subthreshold potentials following a hyperpolarization that removes the inactivation. As a result of these properties, the A-type $\mathrm{K}^{+}$channels are thought to activate following a postspike hyperpolarization and to regulate spike frequency by delaying the next spike in a train (Connor and Stevens, 1971b). However, in rat superior cervical ganglion cells, A-type $\mathrm{K}^{+}$channels are not inactivated at the resting potential; here they also seem to help repolarize the action potential and contribute to its shape (Belluzzi et al., 1985). As a result, in certain neurons of Dro-

\footnotetext{
Received July 10, 1991; revised Oct. 9, 1991; accepted Oct. 18, 1991.

This work was supported by the Howard Hughes Medical Institute. We thank Steven Siegelbaum for critical reading of the manuscript, Harriet Ayers and Andrew Krawetz for typing the manuscript, and Kathrin Hilten and Sarah Mack for preparation of the figures.

Correspondence should be addressed to Eric R. Kandel, M.D., Center for Neurobiology and Behavior, College of Physicians and Surgeons, Columbia University, 722 West 168th Street, New York, NY 10032.

Copyright (C) 1992 Society for Neuroscience 0270-6474/92/120989-12\$05.00/0
}

sophila and Aplysia, A-type $\mathrm{K}^{+}$channels can influence transmitter release by altering the shape of action potential (Jan et al., 1977; Salkoff and Wyman, 1981; Tanouye et al., 1981; Shimahara, 1983).

The existence of large variations in the properties of A-type $\mathrm{K}^{+}$channels in different cells suggests that there must be several types of A-type $\mathrm{K}^{+}$channels (Rudy, 1988). Indeed, several cDNAs encoding kinetically different A-type $\mathrm{K}^{+}$channels have been cloned from the Drosophila Shaker locus (Iverson et al., 1988; Timpe et al., 1988). Moreover, in Drosophila neurons there are additional $\mathrm{A}$-type $\mathrm{K}^{+}$channels that are not affected by mutations in the Shaker locus, indicating that still other genes encode for A-type $\mathrm{K}^{+}$channels (Solc et al., 1987; Baker and Salkoff, 1990). These genetically different channels have different gating characteristics. The voltage-dependent gating of non-Shaker A-type $\mathrm{K}^{+}$channels is similar to conventional A-type $\mathrm{K}^{+}$channels in being inactivated near the resting level, whereas the voltage dependence of Shaker A-type $\mathrm{K}^{+}$channels is shifted to more depolarized potentials (Solc et al., 1987; Baker and Salkoff, 1990). Despite the variety of A-type $\mathrm{K}^{+}$channels, there are few systematic studies relating specific kinetics of different A-type $\mathrm{K}^{+}$ channels to identifiably different cells (Premack et al., 1989; Serrano and Getting, 1989), a necessary prerequisite for studying the roles of A-type $\mathrm{K}^{+}$channels in cellular function and in behavior.

As a first step to elucidate the specific physiological functions of the various A-type $\mathrm{K}^{+}$channels in cell excitability and synaptic transmission, we have carried out in parallel a molecular cloning study of Aplysia $\mathrm{K}^{+}$channels (Pfaffinger et al., 1991; Zhao and Kandel, 1991) and a characterization of the early $\mathrm{K}^{+}$ currents in the identified neurons of Aplysia. We here distinguished three types of early transient $\mathrm{K}^{+}$current and describe their properties. Two of these are comparable to conventional A-type $\mathrm{K}^{+}$currents. These two can be distinguished from one another by their different kinetic rates. A fast A-type $\mathrm{K}^{+}$current is found in some cells [e.g., the left upper quadrant (LUQ) cells], and a slow A-type $\mathrm{K}^{+}$current is found in other cells [e.g., the right upper quadrant (RUQ) cells]. In still other neurons (e.g., $\mathrm{R} 2$ and $\mathrm{R} 15$ ), a third type of transient $\mathrm{K}^{+}$current is found to coexist with conventional A-type $\mathrm{K}^{+}$currents. This third current shows several novel features that distinguish it from conventional A-type $\mathrm{K}^{+}$currents.

\section{Materials and Methods}

Aplysia californica (1-20 gm or 40-150 gm) were anesthetized by the injection of isotonic $\mathrm{MgCl}_{2}$. The ganglia were then dissected out of the animal and treated with $1 \%$ protease (Sigma, type IX) for up to $90 \mathrm{~min}$ 
A1

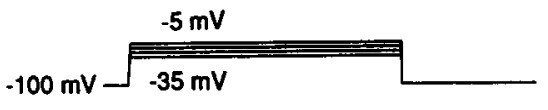

LUQ

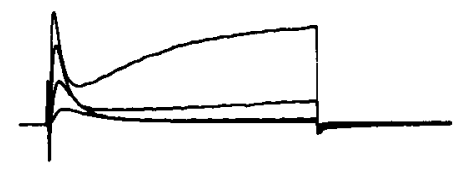

Figure 1. Membrane currents of LUQ $(A)$ and RUQ $(B)$ cells in ASW. $A I$ and $B 1$, The currents of axotomized LUQ $(A I)$ and RUQ cells $(B I)$ in response to depolarizing steps from $-35 \mathrm{mV}$ to -5 $\mathrm{mV}$ in $10 \mathrm{mV}$ increments following a $500 \mathrm{msec}$ prepulse to $-100 \mathrm{mV}$. $A 2$ and $B 2$, The currents of axotomized LUQ $(A 2)$ and RUQ $(B 2)$ in response to the same depolarizing steps following a brief (2 msec) hyperpolarization to $-100 \mathrm{mV}$. Upper traces in $A I$ and $A 2$ show pulse protocols. The holding potential was $-50 \mathrm{mV}$; the duration of the command pulse was $100 \mathrm{msec}$. Command pulses were applied every $10 \mathrm{sec}$.

B1

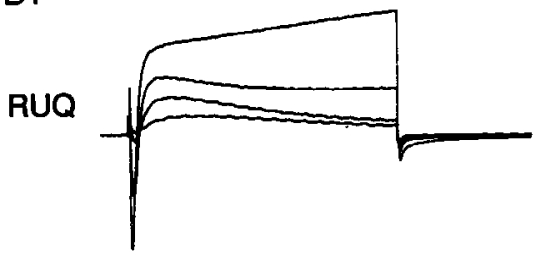

A2
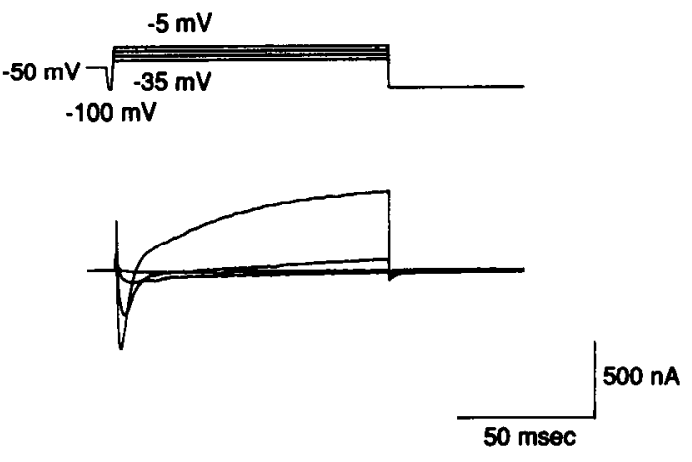

B2

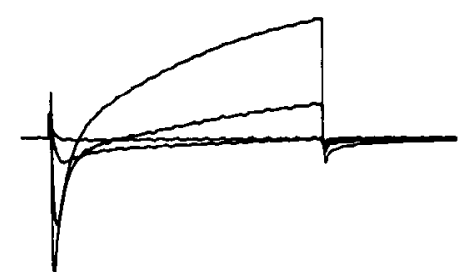

to loosen the connective tissue. The connective capsule covering the ganglion was then removed using fine forceps and microscissors. The ganglion was usually incubated in L-15 medium (Flow Laboratories, McLean, VA) for $24-48 \mathrm{hr}$ at $18^{\circ} \mathrm{C}$ before the experiment. The salt content of the L-15 medium was adjusted to the osmolarity of marine invertebrates. There was no difference in the results between the cultured preparation and the acutely dissected preparation. Unless otherwise noted, the results are expressed as mean \pm SD. All experiments were carried out at room temperature $\left(24-27^{\circ} \mathrm{C}\right)$.

The preparation was pinned to the bottom of an experimental chamber with a volume of about $3 \mathrm{ml}$. The preparation was continuously perfused with the artificial seawater (ASW) or Tris artificial seawater (Tris-ASW). The composition of ASW was as follows (in mM): 460 $\mathrm{NaCl}, 10 \mathrm{KCl}, 55 \mathrm{MgCl}_{2}, 11 \mathrm{CaCl}_{2}, 10 \mathrm{HEPES}(\mathrm{pH}$ was titrated to 7.6 with $\mathrm{NaOH}$ ). The Tris-ASW was an $\mathrm{Na}^{+}$- and $\mathrm{Ca}^{2+}$-free solution of the following composition (in $\mathrm{mM}$ ): 460 tris(hydroxymethyl)aminomethane (Tris), $10 \mathrm{KCl}, 66 \mathrm{MgCl}_{2}, 10 \mathrm{HEPES}$ ( $\mathrm{pH}$ was titrated to 7.6 with $\mathrm{HCl}$ ). In some experiments the $\mathrm{K}^{+}$concentration of the Tris-ASW was changed by replacing Tris with $\mathrm{KCl}$. Most recordings were carried out in TrisASW to block $\mathrm{Na}^{+}$and $\mathrm{Ca}^{2+}$ currents, which also reduced the nonclamped axonal currents. Some experiments were made in ASW using the axotomized preparation to confirm that the present results were not due to the use of the Tris-ASW. The axotomy was done by an undercut using microscissors.

The cells were voltage clamped by a conventional two-microelectrode method as described previously (Pfaffinger et al., 1991). All the data were acquired and analyzed using an IBM PC-AT-compatible computer and the BASIC-FASTLAB system (Indec Systems, Inc., Sunnyvale, CA). Permanent records were produced using a X-Y plotter (model 7470A, Hewlett Packard, San Diego, CA).

The following drugs were used: 4-aminopyridine (4-AP), tetraethylammonium bromide (TEA), forskolin, 1,9-dideoxy-forskolin, 8-(4chlorophenylthio)-adenosine $3^{\prime}, 5^{\prime}$-cyclic monophosphate [8(4CPT)cAMP]. 1,9-Dideoxy-forskolin was obtained from Calbiochem. All other drugs were obtained from Sigma. Forskolin and 1,9-dideoxy-forskolin were dissolved in ethanol or dimethyl sulfoxide (DMSO) as $10 \mathrm{mM}$ or $100 \mathrm{~mm}$ stock solutions, and diluted in the Tris-ASW immediately before use. Other drugs were dissolved in the Tris-ASW just before each experiment. The drugs were usually applied by bath perfusion. 1,9Dideoxy-forskolin dissolved either in ethanol or in DMSO precipitated easily when it was mixed with the Tris-ASW. Because of this difficulty, we introduced a small aliquot of $100 \mathrm{~mm} 1,9$-dideoxy-forskolin dissolved in DMSO directly to the recording chamber (the final concentration of DMSO was less than $1 \%$, which had no effect on currents). Because of the precipitation, the exact concentration of the drug was not known.

\section{Results}

Two distinct transient outward currents in the LUQ and the $R U Q$ cells

When the membrane potential of an axotomized LUQ cell was stepped to potentials more positive than $-50 \mathrm{mV}$, after a hyperpolarizing prepulse to $-100 \mathrm{mV}$, a prominent fast transient outward current was seen following a brief inward current (Fig. $1 A I$ ). The fast transient outward current rose rapidly to a peak and then decayed within 10-20 msec. After a slight delay, other outward currents also activated during the command pulse. The late outward currents are probably composed of both voltagedependent delayed $\mathrm{K}^{+}$currents and $\mathrm{Ca}^{2+}$-activated $\mathrm{K}^{+}$currents. The fast transient outward current was not seen when the depolarizing pulse was applied directly from the holding potential of $-50 \mathrm{mV}$ or following a hyperpolarizing step of only a few milliseconds in duration (Fig. 1A2).

The same pulse protocol illustrated in Figure $1 A 1$ produced quite different currents in the axotomized RUQ cells (Fig. 1BI). The fast transient outward current seen in LUQ cells was not found in RUQ cells. Rather, following the inward current, a slower transient current was seen that overlapped with the activation of other delayed outward currents. This slow transient outward current was also not seen unless a hyperpolarizing prepulse of a sufficient duration was applied (Fig. 1B2). From these results, it would seem that the LUQ and RUQ cells possess kinetically different $\mathrm{A}$-type $\mathrm{K}^{+}$currents. We abbreviate the faster transient outward current as $I_{\text {Afast }}$ and the slower one as $I_{\text {Aslow }}$.

\section{Isolation of $\mathbf{I}_{\text {Afast }}$ and $\mathbf{I}_{\text {Astow }}$ and their ionic mechanisms}

Because both $I_{\text {Afast }}$ and $I_{\text {Aslow }}$ inactivate completely at the holding potential of $-50 \mathrm{mV}$, it was possible to isolate these currents by subtracting the currents obtained without a hyperpolarizing prepulse. To eliminate interfering $\mathrm{Na}^{+}$and $\mathrm{Ca}^{2+}$ currents, the measurements were carried out in Tris-ASW (see Materials and Methods). Figure 2, $A I$ and $B 1$, shows the families of membrane currents in LUQ and RUQ cells recorded in Tris-ASW. $I_{\text {Afast }}$ and $I_{\text {Aslow }}$ can now be seen clearly because the $\mathrm{Ca}^{2+}$-activated $\mathrm{K}^{+}$ 

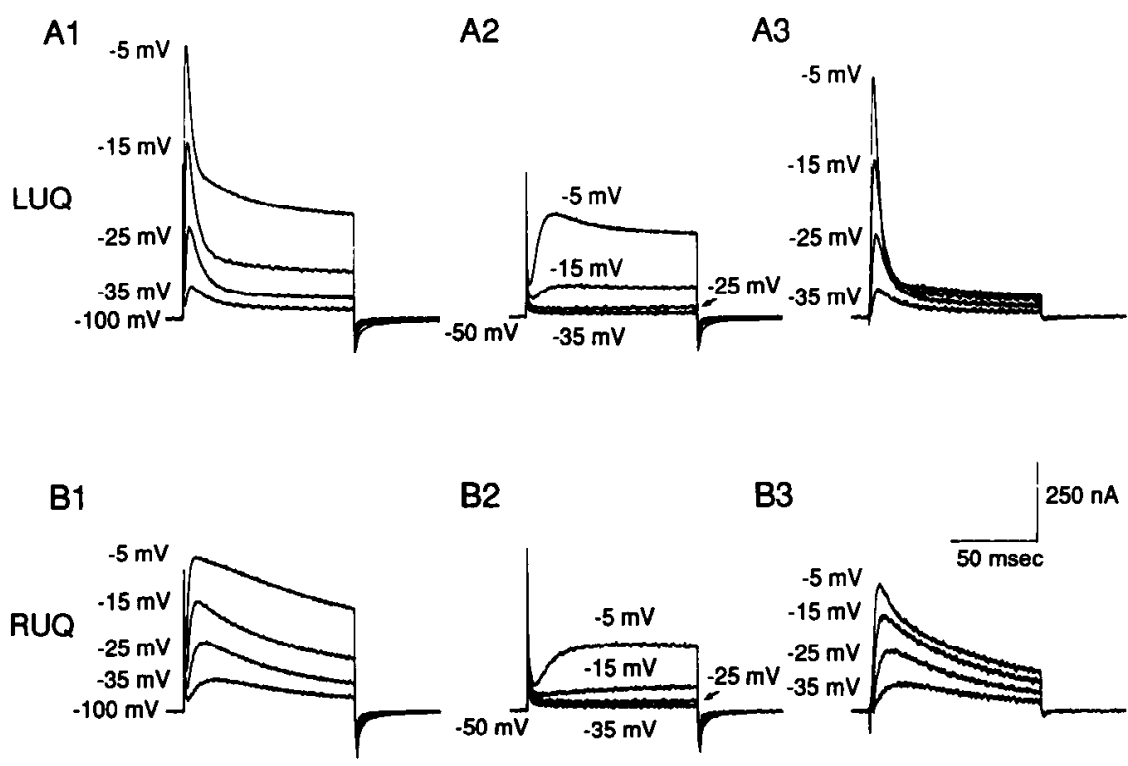

C

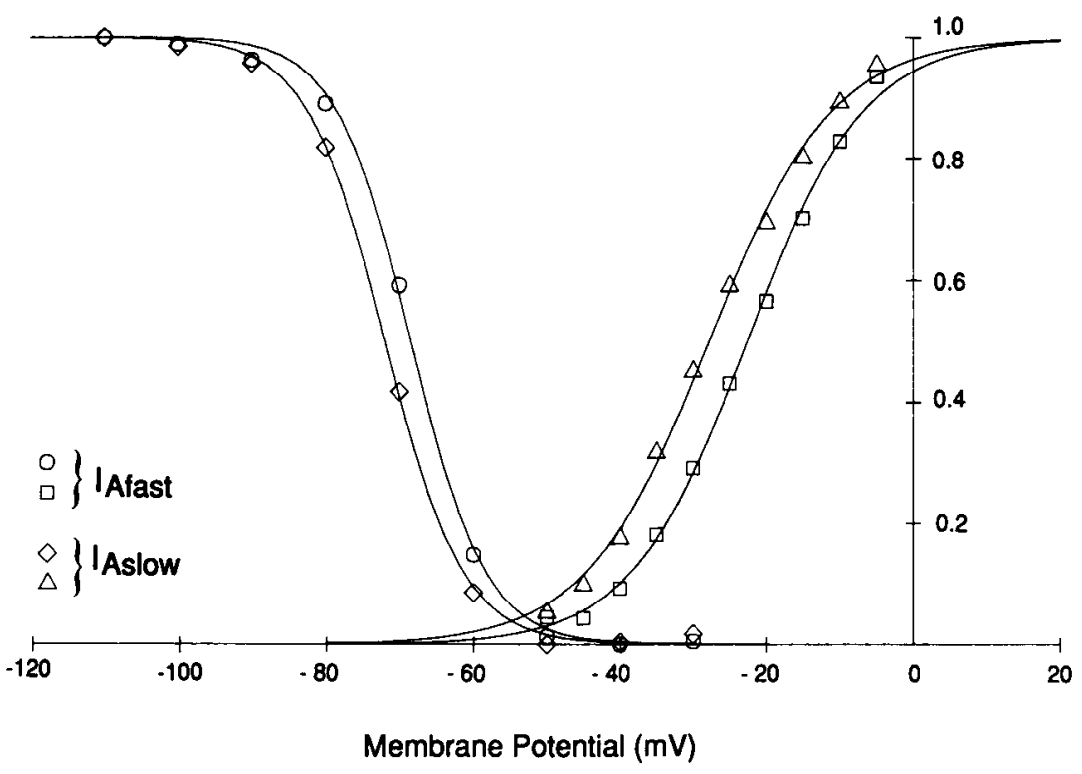

Figure 2. Membrane currents of LUQ $(A)$ and RUQ $(B)$ cells in Tris-ASW. The holding potential was $-50 \mathrm{mV}$; the duration of the command pulse was 100 msec. Command pulses were applied every $10 \mathrm{sec}$. The currents in response to steps from $-35 \mathrm{mV}$ to $-5 \mathrm{mV}$ in 10 $\mathrm{mV}$ increments are shown. $A I$ and $B I$, The currents elicited by the command pulses following a $500 \mathrm{msec}$ prepulse to $-100 \mathrm{mV} . A 2$ and $B 2$, The currents obtained by the command pulses following $2 \mathrm{msec}$ hyperpolarization to $-100 \mathrm{mV} . A 3$ and $B 3$, The difference currents obtained by subtracting the currents in $A 2$ (or $B 2$ ). from those in $A l$ (or $B I$ ). $C$, The activation and the steady-state inactivation of $I_{\text {Arast }}$ (squares, circles) and $I_{\text {Aslow }}$ (triangles, diamonds). The methods for obtaining these curves are described in Results. The smooth lines are the Boltzmann functions of the form $I=1 /\left(1+\exp \left(\left(V_{m}\right.\right.\right.$ $\left.\left.-V_{y_{2}}\right) / k\right)$ ). The midpoints $\left(V_{y_{2}}\right)$ and the slope factors $(k)$ are, respectively, as follows (in $\mathrm{mV}$ ): -22.5 and -8.0 (squares), -27.7 and -8.4 (triangles), -68.4 and 5.1 (circles), -72.0 and 5.3 (diamonds). current as well as $\mathrm{Na}^{+}$and $\mathrm{Ca}^{2+}$ currents are blocked. These results also suggest that both transient currents do not depend on $\mathrm{Ca}^{2+}$ influx. Both $I_{\text {Afast }}$ and $I_{\text {Aslow }}$ disappeared completely if the hyperpolarizing prepulse was omitted (Fig. 2A2,B2). The remaining currents in LUQ and RUQ cells appear different due to the presence of another transient component, which also does not inactivate at the holding potential of $-50 \mathrm{mV}$ in LUQ cells (see the current at $-5 \mathrm{mV}$ in Fig. 2A2). This other transient current will be described separately below. $I_{\text {Afast }}$ and $I_{\text {Aslow }}$ were isolated by subtracting the currents obtained without the prepulse from the ones obtained with the prepulse (Fig. 2A3,B3). Both $I_{\text {Afast }}$ and $I_{\text {Aslow }}$ activaled in a voltage-dependent manner with a threshold of around $-50 \mathrm{mV}$. $I_{\text {Afast }}$ reached its peak within 2-6 msec depending on the voltage, whereas $I_{\text {Aslow }}$ took 5-20 msec to reach its peak.

The inactivation of $I_{\text {Afast }}$ was virtually complete with a few tens of milliseconds (Fig. 2A3). There remained, however, some currents that did not inactivate even when the longer command pulse (up to $1 \mathrm{sec}$ ) was used (not shown). Although we cannot exclude the possibility that some components of $I_{\text {Afast }}$ do not inactivate completely, we believe that most of the remaining current is probably due to the incomplete subtraction of another current that partially inactivates at $-50 \mathrm{mV}$. Several arguments favor this idea. (1) The decay of the current at -10 or $-5 \mathrm{mV}$ frequently showed an abrupt transition between the fast and slowly decaying components. (2) The ratio of the slowly decaying component to the fast one was variable from cell to cell; at -10 $\mathrm{mV}$ it ranged from 0.05 to 0.40 . (3) Externally applied forskolin (see below) selectively depressed the fast component without affecling the slow component. Because the inactivation of $I_{\text {Aslow }}$ was slow compared to that of $I_{\text {Afast }}$, the current continued to decrease throughout the $100 \mathrm{msec}$ command pulse (Fig. 2B3). However, when a sufficiently long pulse (e.g., 1 sec) was used, complete inactivation of $I_{\text {Asiow }}$ was obtained.

The reversal potentials of $I_{\text {Afast }}$ and $I_{\text {Aslow }}$ in the Tris-ASW, obtained by measurement of the tail current reversal, were -89.0 
Figure 3. Time-dependent inactivation of $I_{\text {Afast }}$ and $I_{\text {Aslow }} A I, I_{\text {Afast }}$ in response to the indicated steps following a $500 \mathrm{msec}$ prepulse to $-100 \mathrm{mV}$. Imposed lines are exponential functions of the form $I(t)=a_{1} \exp \left(-t / \tau_{1}\right)+a_{2} \exp (-t)$ $\left.\tau_{2}\right)+c$. The time constants $\left(\tau_{1}\right.$ or $\tau_{1}$ and $\tau_{2}$ ) are as follows (in msec): $17.3(-35$ $\mathrm{mV}) ; 10.8(-25 \mathrm{mV}) ; 5.8$ and 153.0 $(-15 \mathrm{mV})$. $A 2$, The relationship between $\tau_{1}$ and membrane potential. Circles are mean values and bars indicate $\mathrm{SD}$ of the mean $(n=10) . B 1, I_{\text {Aslow }}$ in response to the indicated steps following a $1 \mathrm{sec}$ prepulse to $-100 \mathrm{mV}$. Imposed lines are single exponentials. The time constants are as follows (in $\mathrm{msec}$ ): 65.4 (-35 mV); 50.8 (-25 mV); 49.0 $(15 \mathrm{mV}) . B 2$, The relationship between the time constant and the membrane potential. Circles are mean values and bars indicate SD of the mean $(n=6)$.
A1

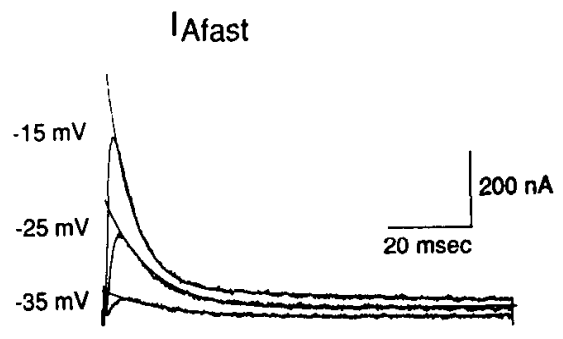

$\mathrm{A} 2$

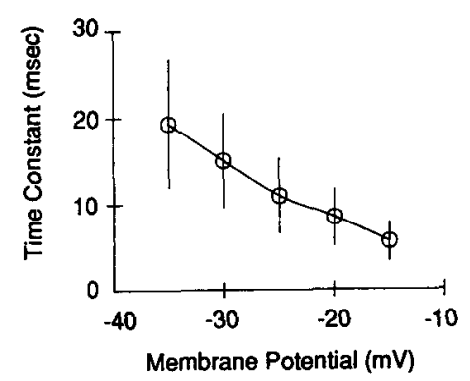

B1

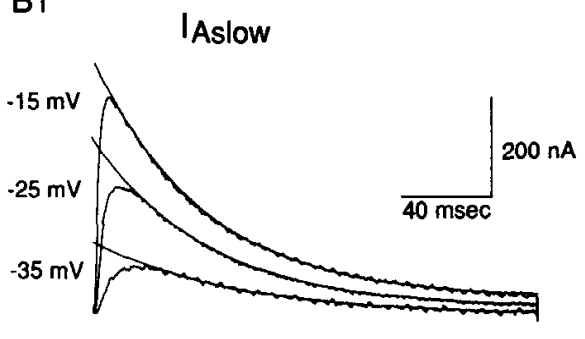

B2

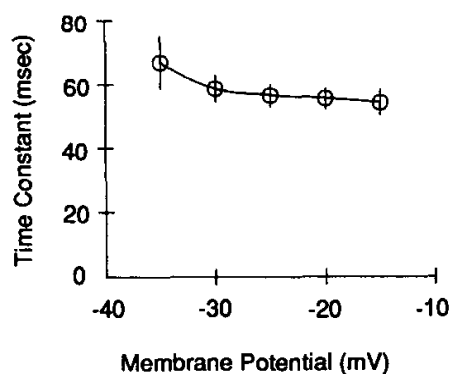

$\pm 7.6 \mathrm{mV}(n=4)$ and $-96.7 \pm 2.3 \mathrm{mV}(n=6)$, respectively. When the external $\mathrm{K}^{+}$concentration was increased 10 -fold, the reversal potentials of $I_{\text {Afas }}$ and $I_{\text {Aslow }}$ became $-32.8 \pm 4.5 \mathrm{mV}$ $(n=3)$ and $-40.0 \pm 3.5 \mathrm{mV}(n=3)$, respectively. These changes of the reversal potentials are almost exactly those predicted from the $\mathrm{K}^{+}$Nernst equation. Although we have not yet tested the permeability ratio of $\mathrm{Na}^{+}$to $\mathrm{K}^{+}$, it would be safe to say that both $I_{\text {Afast }}$ and $I_{\text {Aslow }}$ are $\mathrm{K}^{+}$currents.

The activation and the steady-state inactivation of $\mathrm{I}_{\text {Afost }}$ and I $_{\text {siow }}$

The activation of both $I_{\text {Afast }}$ and $I_{\text {Aslow }}$ were examined by constructing peak conductance versus voltage curves (Fig. $2 \mathrm{C}$ ). The peak conductance was calculated by dividing the peak current, measured at each potential, with the driving force (mean reversal potentials described above were used to calculate the driving force). The relation between the resulting conductances $\left(G_{p}\right)$ and the voltages $\left(V_{m}\right)$ was fit to a Boltzmann function of the form $G_{p}=G_{\max } /\left(1+\exp \left(\left(V_{m}-V_{r_{2}}\right) / k\right)\right)$, to estimate the maximum conductance $\left(G_{\max }\right)$. The midpoint of the curve $\left(V_{1 / 2}\right)$ is the potential where $G_{p}$ becomes half of $G_{\max }$, and the slope factor of the curve is $k$. The estimated $G_{\max }$ was used to normalize the conductances, and the normalized values were then plotted against the voltages as shown in Figure $2 C$. The midpoint and the slope of the Boltzmann function for $I_{\text {Afast }}$ in the LUQ cells were $-23.6 \pm 2.0 \mathrm{mV}$ and $-8.2 \pm 0.7 \mathrm{mV}(n=11)$, respectively, for $I_{\text {Aslow }}$ in the RUQ cells they were $-27.8 \pm 2.1 \mathrm{mV}$ and -8.4 $\pm 0.4 \mathrm{mV}(n=8)$, respectively.

To examine the steady-state inactivation of $I_{\text {Afast }}$ and $I_{\text {Aslow }}$, the peak current was measured at $-20 \mathrm{mV}$ after varying a 500 msec prepulse (or a $1 \mathrm{sec}$ prepulse in the case of RUQ cells) in $10 \mathrm{mV}$ increments from -110 to $-30 \mathrm{mV}$. The measured currents were normalized to the value obtained with a prepulse to
$-110 \mathrm{mV}$ and then plotted against the prepulse voltages (Fig. $2 C$ ). The resulting steady-state inactivation curve could be approximated by a Boltzmann function. The midpoint and the slope were, respectively, $-69.7 \pm 4.1 \mathrm{mV}$ and $5.7 \pm 0.8 \mathrm{mV}$ for $I_{\text {Afast }}$ in the LUQ cells $(n=15)$ and $-73.2 \pm 2.2 \mathrm{mV}$ and $4.7 \pm 0.4 \mathrm{mV}$ for $I_{\text {Aslow }}$ in the RUQ cells $(n=7)$.

Time-dependent inactivation of $\mathrm{I}_{\text {Afast }}$ and $\mathrm{I}_{\text {Aslow }}$

The decay of both $I_{\text {Afast }}$ and $I_{\text {Aslow }}$ were fit with exponential functions. Figure $3, A l$ and $B I$, shows families of $I_{\text {Afast }}$ and $I_{\text {Aslow }}$ with superimposed exponentials. For both $I_{\text {Arast }}$ and $I_{\text {Asluw }}$, the timedependent inactivation could be well fit with a single exponential function except for $I_{\text {Afast }}$ at potentials more positive than -20 $\mathrm{mV}$, where a second exponential was needed to fit the slower decay rate. The time constants obtained by this fitting are plotted against the voltages in Figure $3, A 2$ and $B 2$. Because the slow component of $I_{\text {Afast }}$ may be a contaminant as described above, the slower time constants are not included in this article. The time constant for the decay of $I_{\text {Afast }}$ was voltage dependent, ranging from about $20 \mathrm{msec}$ at $-35 \mathrm{mV}$ to $5 \mathrm{msec}$ at $-15 \mathrm{mV}$. On the contrary, the time constant for the decay of $I_{\text {Aslow }}$ was essentially voltage independent, having the value of 50-60 msec.

The onset of and the recovery from the inactivation of $\mathrm{I}_{\text {Afast }}$ and Islow

The time course for the onset of the inactivation at more negative potentials was examined using a double-pulse protocol. Figure 4 shows an example of one such experiment for $I_{\text {Afast }}$ in an LUQ cell. To measure the onset of inactivation, the test pulses to $-20 \mathrm{mV}$ were applied following progressively longer depolarized conditioning pulses to $-50 \mathrm{mV}$ (see the inset of Fig. $4 A l$ ). The longer the duration of the conditioning pulse, the smaller $I_{\text {Afast }}$ became (Fig. 4AI). The peak currents during 
A1

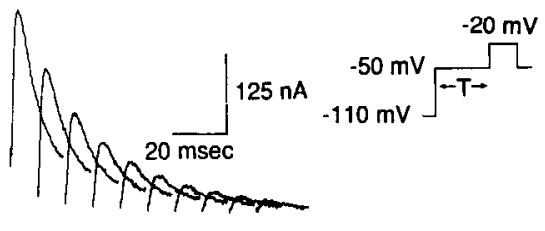

B1

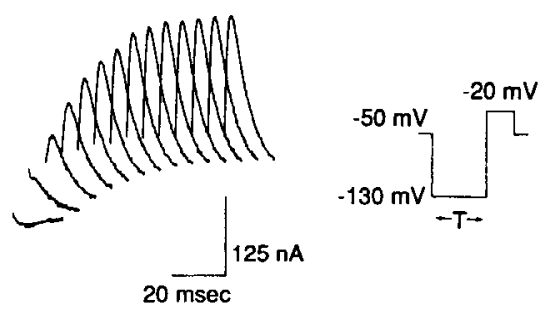

A2

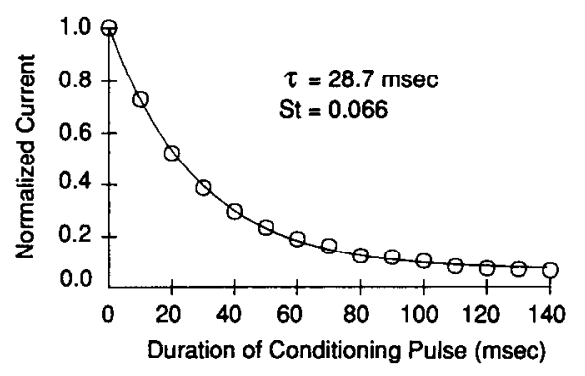

B2

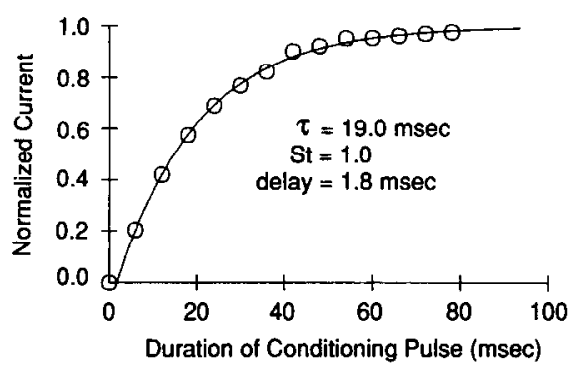

Figure 4. The onset of and the recovery from the inactivation of $I_{\text {Afast }} . A 1, I_{\text {Afast }}$ elicited by a 20 msec test pulse to $-20 \mathrm{mV}$ following conditioning pulses to $-50 \mathrm{mV}$ of variable duration (from $0 \mathrm{msec}$ to $90 \mathrm{msec}$ in $10 \mathrm{msec}$ increments). The inset shows the pulse protocol. Before the conditioning pulse, the membrane potential was held at $-110 \mathrm{mV}$ for $500 \mathrm{msec}$ to remove the inactivation of $I_{\text {Afasi }} . A 2$, The onset of the inactivation at -50 $\mathrm{mV}$. Circles are the peak $I_{\text {Afast }}$ normalized to the value obtained without the conditioning pulse $\left(I_{n 1}\right)$, plotted against the duration of the pulse. The smooth line is a single exponential of the form $I_{n 1}=\mathrm{St}+(1-\mathrm{St}) \exp (-t / \tau)$. The time constant $(\tau)$ is $28.7 \mathrm{msec}$, and the steady-state value (St) is 0.066 . BI, $I_{\text {Afast }}$ elicited by a $20 \mathrm{msec}$ test pulse to $-20 \mathrm{mV}$ following conditioning pulses to $-130 \mathrm{mV}$ of variable duration (from $0 \mathrm{msec}$ to 78 $\mathrm{msec}$ in $6 \mathrm{msec}$ increments). The inset shows the pulse protocol. Before the pulse to $-130 \mathrm{mV}$, the membrane potential was held at $-50 \mathrm{mV}$ to inactivate $I_{\text {Afast }} . B 2$, The recovery from inactivation at $-130 \mathrm{mV}$. Circles are the peak $I_{\text {Afast }}$ normalized to the value obtained following a conditioning pulse of $500 \mathrm{msec}$ duration $\left(I_{n 2}\right)$, plotted against the duration of the pulse. The smooth line is a single exponential of the form $I_{n 2}=S t(1-\exp (-(t$ $-d) / \tau)$ ). $\tau$ is $19.0 \mathrm{msec}$, St is 1.0 , and a delay $(d)$ is $1.8 \mathrm{msec}$.

the test pulse were normalized to the peak current obtained without a conditioning pulse, and plotted against the duration of the pulse (Fig. 4A2). The time course of the onset of inactivation converged to a steady-state inactivation along a single exponential function.

The recovery from inactivation was obtained using a similar pulse protocol except the cell was held at $-50 \mathrm{mV}$, a potential at which both $I_{\text {Afast }}$ and $I_{\text {Aslow }}$ inactivate completely, and progressively longer hypcrpolarizing conditioning pulses were applied to remove inactivation. Figure $4 B 1$ shows the progressive recovery of $I_{\text {Afast }}$ by increasing the duration of a conditioning pulse to $-130 \mathrm{mV}$. The currents were normalized to the one obtained after a $500 \mathrm{msec}$ conditioning pulse to $-130 \mathrm{mV}$ and then plotted against the duration of the pulse (Fig. $4 B 2$ ). The time course of the recovery was also approximated by a single exponential function, but a delay was required to better fit the early phase of the recovery. The delay was voltage dependent and became longer with more depolarized conditioning pulses. In the case of $I_{\text {Afast }}$, the delay was $0.8-4 \mathrm{msec}$ for conditioning voltages ranging from -130 to $-70 \mathrm{mV}$. The delay was $1.5-$ $25 \mathrm{msec}$ in $I_{\text {Aslow }}$, in the same voltage range.

Figure 5 illustrates the time constants for onset and recovery from inactivation obtained by the double-pulse experiments as well as the steady-state values of inactivation plotted as a function of the conditioning voltages. In both $I_{\text {Afast }}$ and $I_{\text {Aslow }}$, the time constants were voltage dependent with the largest values around $-70 \mathrm{mV}$. At $-70 \mathrm{mV}$, it was possible to obtain both the onset of and the recovery from inactivation. In the case of $I_{\text {Aslow }}$, both time constants obtained at $-70 \mathrm{mV}$ were similar (Fig. 5B1). However, in the case of $I_{\text {Afass }}$, the time constant obtained from the onset of the inactivation was much faster than that obtained from the recovery (Fig. $5 A I$ ). The smooth lines in Figure 5, $A 2$ and $B 2$, are the Boltzmann functions using the midpoints and the slope factors obtained by the measurements shown in Figure 2. The steady-state inactivation of $I_{\text {Aslow }}$ measured in these experiments coincided well with the Boltzmann function measured previously (Fig. $5 B 2$ ), while the values for $I_{\text {Afast }}$ deviated slightly from the Boltzmann function except at the most hyperpolarized voltages (Fig. 5A2).

\section{A novel transient $\mathrm{K}^{+}$current activates at more positive voltages}

In neuron R2, a shoulder was observed during the decaying phase of $I_{\text {Afast }}$ when depolarizing command pulses following a prepulse to $-100 \mathrm{mV}$ were applied with a relatively long interpulse interval $(>10 \mathrm{sec})$ from a hyperpolarized holding potential such as $-80 \mathrm{mV}$ (Fig. $6 A 1$ ). This result suggests the existence of another transient outward current. This current seems to require a relatively long hyperpolarization to remove inactivation of the current. Because $I_{\text {Afast }}$ is completely inactivated by a prepulse to $-50 \mathrm{mV}$ as described above, the effect of a $1 \mathrm{sec}$ prepulse to $-50 \mathrm{mV}$ was examined. As shown in Figure $6 A 2$, using such pulse protocol a transient outward cur- 
A1

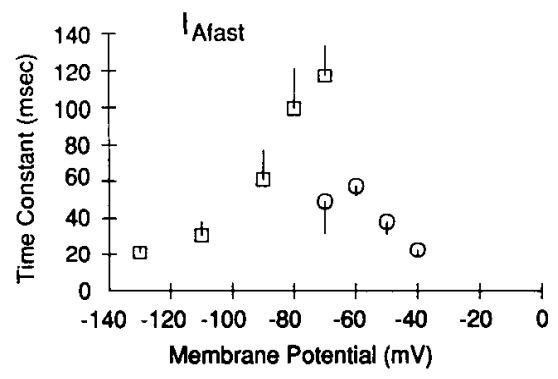

B1

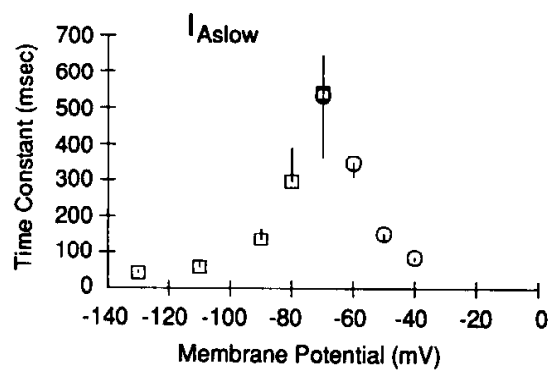

A2

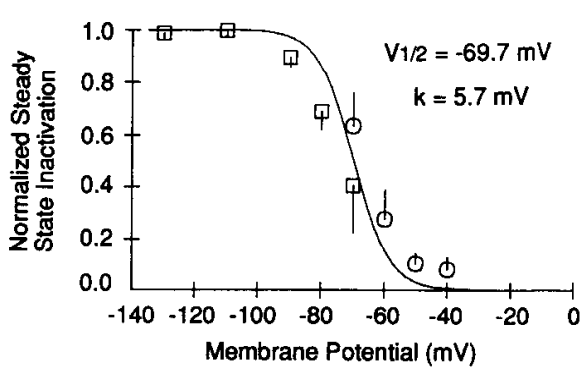

B2

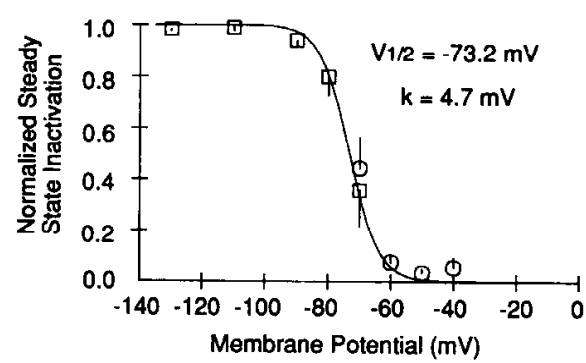

Figure 5. Voltage dependence of the inactivation of $I_{\text {Afast }}(A)$ and $I_{\text {Aslow }}(B)$. $A l$, The time constants $(\tau)$ for the onset of and the recovery from the inactivation of $I_{\text {Afass }}$, plotted against membrane potential. Circles, mean $\tau$ obtained from the onset of the inactivation; squares, mean $\tau$ obtained from the recovery from inactivation. Bars indicate SD of the mean; $n=8$ for each point, except for $-80 \mathrm{mV}$, where the $n=6$. $A 2$, The estimated steady-state inactivation of $I_{\text {Afast }}$ obtained by the fitting shown in Figure 4, plotted against membrane potential. The smooth line is the Boltzmann function having a midpoint of $-69.7 \mathrm{mV}$ and a slope factor of $5.7 \mathrm{mV}$. The data are means obtained from the experiments in Figure 2. Circles, mean steady-state inactivation obtained from the onset of inactivation; squares, mean steady-state inactivation obtained from the recovery from inactivation. Bars indicate SD of the mean. $B 1, \tau$ for the onset of and the recovery from inactivation of $I_{\text {Aslow }}$, plotted against membrane potential. The symbols are the same as in $A 1$. Circles, $n=7$; squares, $n=6 . B 2$, The estimated steady-state inactivation of $I_{\text {Aslow }}$ obtained by the fitting (as described above for $I_{\text {Afsis }}$ ) plotted against membrane potential. The smooth line is the Boltzmann function having a midpoint of $-73.2 \mathrm{mV}$ and a slope factor of $4.7 \mathrm{mV}$. The data are means obtained from the experiments as shown in Figure 2 . The symbols are the same as in $A 2$.

rent having different activation and inactivation rates from those of $I_{\text {Afast }}$ and $I_{\text {Astow }}$ became clearly evident. We call this transient outward current $I_{\text {Adepol }}$ because it displays A-type $\mathrm{K}^{+}$current gating at more depolarized voltages.

Because TEA blocks several types of $\mathrm{K}^{+}$currents, including delayed $\mathrm{K}^{+}$currents in Aplysia neurons (Hermann and Gorman, 1981), we tested whether TEA could separate $I_{\text {Adepol }}$ from delayed outward currents. $I_{\text {Afast }}$ was inactivated by using a prepulse to $-50 \mathrm{mV}$. Without TEA, a prominent $I_{\text {Adepot }}$ was seen as well as delayed outward currents in R2 (Fig. $6 B I$ ); in R15 $I_{\text {Adepol }}$ was less prominent because of the relatively large delayed outward currents (Fig. 6B2). In both neurons total outward current was greatly reduced by $50 \mathrm{~mm}$ TEA, especially at the end of pulses, but $I_{\text {Adepol }}$ was not much reduced in either R2 or in $\mathrm{R} 15$. The resulting TEA-insensitive currents in R15 were very similar to those in $\mathrm{R} 2$ and showcd apparent inactivation. Time-dependent inactivation observed in the presence of TEA is not due to the time-dependent block by TEA. At voltages less positive than $0 \mathrm{mV}$, where delayed outward currents were not well developed, $50 \mathrm{~mm}$ TEA had little effect on membrane currents. Also, TEA-insensitive transient currents as shown in Figure $6 B$ were never observed in other cells that do not have an early transient component superimposed on the delayed outward currents. However, we could not rule out a subtle modification of the inactivation kinetics by TEA. Nevertheless, these results suggest that $I_{\text {Adepo }}$ is relatively insensitive to external TEA and that R15 also possesses $I_{\text {Adepol }}$, although it is not clearly evident in the absence of TEA. Following TEA treatment, a sizable $I_{\text {Adepol }}$ was also revealed in the LUQ cells (not shown).

In the Tris-ASW containing $50 \mathrm{~mm}$ TEA and $10 \mathrm{~mm} \mathrm{~K}^{+}$, the tail current of $I_{\text {Adepol }}$ measured from the peak of activation was reversed at $-55.5 \pm 2.8 \mathrm{mV}$ in $\mathrm{R} 2(n=6)$, or at $-52.9 \pm 6.4$ $\mathrm{mV}$ in $\mathrm{R} 15(n=5)$. When $\left[\mathrm{K}^{+}\right]_{\text {out }}$ was increased 10 times, the reversal potential was shifted to $-25.5 \pm 3.9 \mathrm{mV}$ in R2 $(n=$ $3)$ and $-26.1 \pm 7.1 \mathrm{mV}$ in $\mathrm{R} 15(n=4)$. These results suggest that $I_{\text {Adepol }}$ is mainly but not exclusively carried by $\mathrm{K}^{+}$; however, the apparent reduced selectivity to $\mathrm{K}^{+}$of $I_{\text {Adepol }}$, compared to $I_{\text {Afast }}$ and $I_{\text {Aslow }}$, may be due to incomplete isolation of $I_{\text {Adepol }}$ from other currents.

\section{Isolation of $\mathrm{I}_{\text {Adepol }}$ from currents insensitive to $50 \mathrm{mM}_{\mathrm{M}} \mathrm{TEA}$}

As evident in Figure $6 B$, there are still noninactivating components of membrane current in R2 and R15, even in the presence of $50 \mathrm{~mm}$ TEA. Such components could be separated from $I_{\text {Adepol }}$ as shown in Figure 7. In the Tris-ASW containing $50 \mathrm{~mm}$ TEA, $I_{\text {Adepol }}$ as well as the remaining outward currents were obtained in response to command pulses following a $1 \mathrm{sec}$ prepulse to $-50 \mathrm{mV}$ (Fig. $7 \mathrm{Al}$ ). $I_{\text {Adepol }}$ could be inactivated completely by a $2 \mathrm{sec}$ prepulse to $-20 \mathrm{mV}$ (Fig. 7A2). Figure $7 A 3$ shows difference currents obtained by subtraction of the currents in Figure $7 A 2$ from those in Figure $7 A 1$, indicating that this subtraction method works quite well to isolate $I_{\text {Adepol }} . I_{\text {Adepol }}$ iso- 
A1
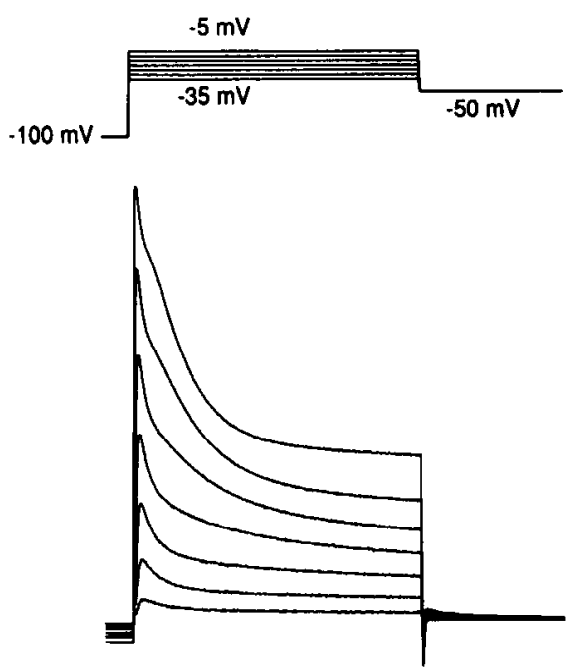

B1

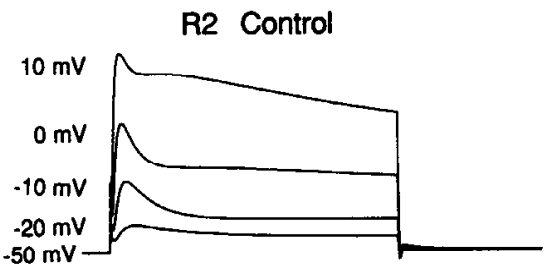

B2

R15 Control

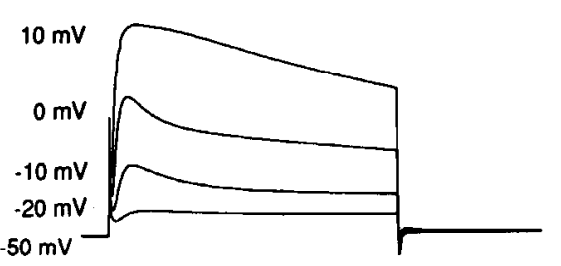

A2
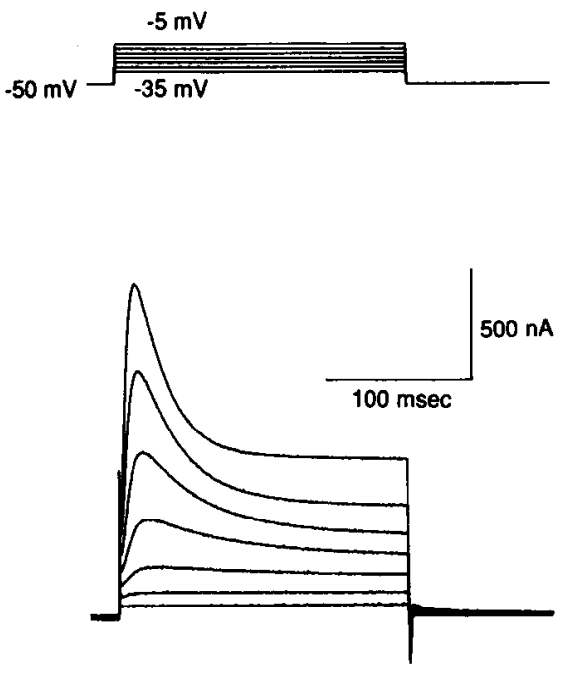

$50 \mathrm{mM}$ TEA

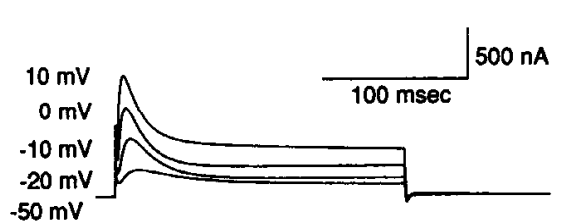

Figure 6. A, Outward currents of R2 recorded in Tris-ASW. Holding potential was $-80 \mathrm{mV}$. Command pulses of $200 \mathrm{msec}$ duration, from $-35 \mathrm{mV}$ to $-5 \mathrm{mV}$ in $5 \mathrm{mV}$ increments, were applied every $20 \mathrm{sec}$ following a 1 sec prepulse to $-100 \mathrm{mV}(A I)$ or $-50 \mathrm{mV}$ $(A 2) . B$, Effect of $50 \mathrm{~mm}$ TEA on outward currents in $\mathrm{R} 2(B I)$ and $\mathrm{R} 15(B 2)$. Depolarizing steps to indicated voltages were applied every $20 \mathrm{sec}$ following a 1 sec prepulse to $-50 \mathrm{mV}$. Holding potential was $-80 \mathrm{mV}$. lated by this method showed voltage-dependent activation, reaching its peak within 4-20 msec, depending on the voltage. In contrast, the time-dependent inactivation of $I_{\text {Adepol }}$ was almost independent of membrane potential (see below).

\section{Activation and Inactivation of $\mathrm{I}_{\text {Adepol }}$}

Figure $7 B$ illustrates activation and inactivation of $I_{\text {Adepol }}$ in R2. Peak conductances were calculated using a mean reversal potential of $-55.5 \mathrm{mV}$. The peak conductance-voltage curve could be well fit to the Boltzmann equation (Fig. 7B3, squares). $V_{1 / 2}$ and $k$ were, respectively, $-15.6 \pm 2.6 \mathrm{mV}$ and $-6.4 \pm 0.4 \mathrm{mV}$ in $\mathrm{R} 2(\mathrm{n}=7)$ and $-12.0 \pm 3.4 \mathrm{mV}$ and $-7.5 \pm 0.7 \mathrm{mV}$ in $\mathrm{R} 15(n=8)$.

The steady-state inactivation of $I_{\text {Adepol }}$ was measured using a two-pulse method. Inactivation of $I_{\text {Adepol }}$ was rather complex and dependent on the duration of conditioning pulse. To obtain a quasi steady-state inactivation curve, we empirically set the duration of conditioning pulse to $2 \mathrm{sec}$, because this duration was enough to inactivate $I_{\text {Adepol }}$ completely at $-20 \mathrm{mV}$. Figure
$7 B 2$ shows $I_{\text {Adepol }}$ at $-10 \mathrm{mV}$ following conditioning pulses to several voltages ( $20 \mathrm{msec}$ gap was inserted between conditioning pulse and test pulse). Normalized $I_{\text {Adepol }}$ was plotted against conditioning voltage and fitted to the Boltzmann equation (Fig. 7 B3, circles). $V_{1 / 2}$ and $k$ were, respectively, $-38.1 \pm 1.6 \mathrm{mV}$ and 3.2 $\pm 0.3 \mathrm{mV}$ in $\mathrm{R} 2(n=7)$ and $-30.9 \pm 3.9 \mathrm{mV}$ and $4.1 \pm 0.3$ $\mathrm{mV}$ in $\mathrm{R} 15(n=7)$. Although slope factors for both activation and inactivation were similar between $\mathrm{R} 2$ and $\mathrm{R} 15, V_{1 / 2}$ for activation and inactivation curves of $I_{\text {Adepol }}$ in R 15 were consistently more depolarized than those in $\mathrm{R} 2$.

\section{Time-dependent inactivation of $\mathrm{I}_{\text {Adepol }}$}

Time-dependent inactivation of $I_{\text {Adepol }}$ observed in response to a depolarizing step was well fit to double exponentials, except at membrane potentials less than $0 \mathrm{mV}$, at which a single exponential was usually enough to describe the current decay. Figure $8 A$ shows $I_{\text {Adepor }}$ in R15 with imposed exponentials, and fast and slow time constants of exponentials ( $\tau_{\text {fast }}$ and $\left.\tau_{\text {slow }}\right)$ are 
Figure 7. Isolation of $I_{\text {Adepol }}(A)$ and its activation and inactivation $(B) . A I$, Outward currents recorded in the TrisASW containing $50 \mathrm{~mm}$ TEA. Command pulses were applied every $20 \mathrm{sec}$ following a $1 \mathrm{sec}$ prepulse to $-50 \mathrm{mV}$. Holding potential was $-80 \mathrm{mV}$. The pulse protocol is illustrated in the lower left, and the membrane currents obtained between the arrows are shown. $A 2$, Outward currents recorded in the Tris-ASW containing $50 \mathrm{~mm}$ TEA by the pulse protocol as shown in the lower right. The membrane currents obtained between the arrows are shown. A3, Difference currents obtained by subtracting currents in $A 2$ from currents in $A l$. $B 1, I_{\text {Adepol }}$ isolated by the method shown in $A . B 2, I_{\text {Adepol }}$ at $-10 \mathrm{mV}$ following a $2 \mathrm{sec}$ prepulse to indicated voltages. No subtraction was performed. B3, Activation (squares) and quasi steady-state inactivation (circles) of $I_{\text {Adepol }}$. Each point and imposed curves were obtained as described in Results. $V_{4 b}$ and $k$ for activation and inactivation are indicated near each curve. Cells: R15 $(A 1-A 3)$, R2 (B1-B3).
A1
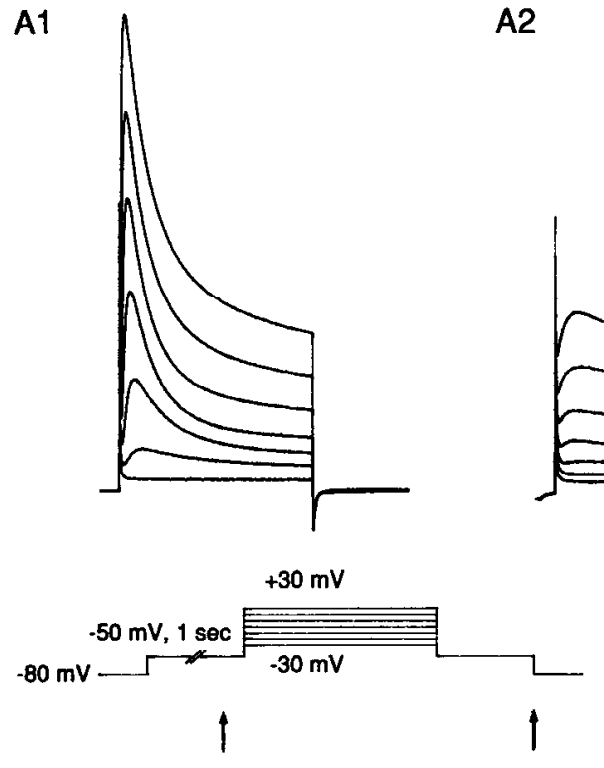

B1

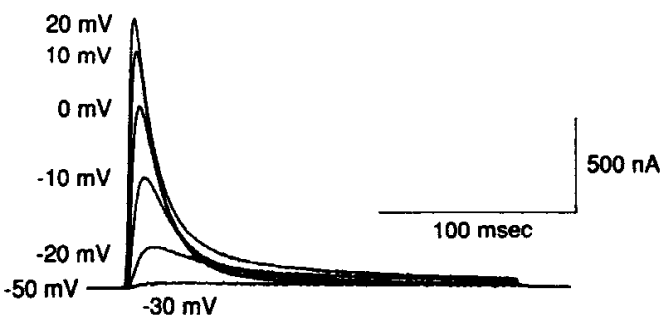

82

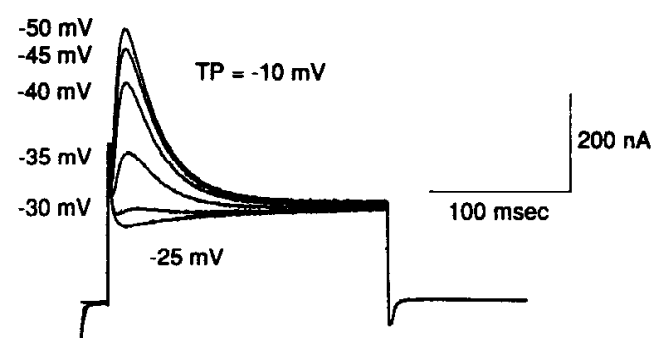

A3
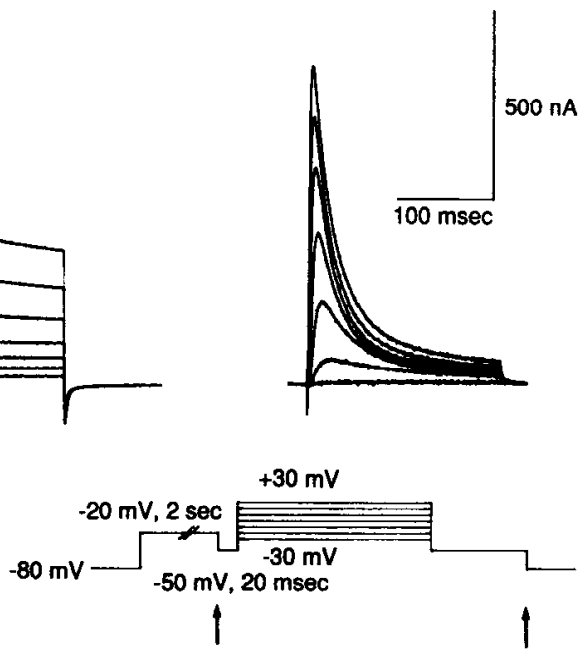

B3

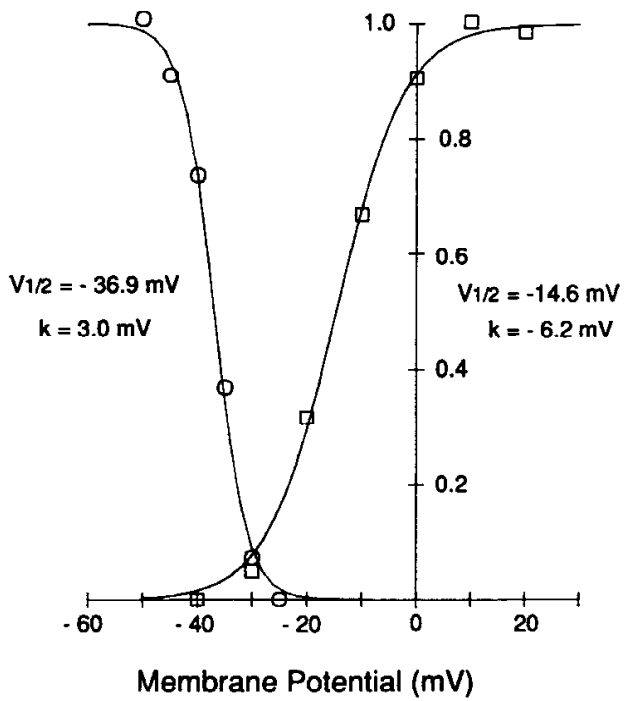

plotted against membrane potential in Figure $8 B$. Beyond $0 \mathrm{mV}$ (i.e., near or at full activation), $\tau_{\text {fast }}$ was fairly constant (about $20 \mathrm{msec}$ ), with a slight tendency to become longer at more depolarized potential (Fig. $8 B$, circles). In contrast, $\tau_{\text {slow }}$ was at a minimum at $20 \mathrm{mV}$ and became longer at both more depolarized and more hyperpolarized potentials (Fig. $8 B$, squares). Although the ratio of the fast component to the slow one became smaller with membrane depolarization, more than $80 \%$ of $I_{\text {Adepol }}$ inactivated with $\tau_{\text {fast }}$ in the voltage range from -20 to $50 \mathrm{mV}$. Similar results were obtained for $I_{\text {Adepol }}$ in R2, although inactivation of $I_{\text {Adepol }}$ in R2 was slightly faster than that in R15 ( $\tau_{\text {fast }}$ and $\tau_{\text {slow }}$ of $I_{\text {Adepol }}$ in R2 were 5-10 msec and 100-150 msec shorter, respectively). $\tau_{\text {slow }}$ may reflect the slow inactivation of $I_{\text {Adepol }}$ (see below), or $I_{\text {Adepol }}$ isolated by our method may be still contaminated by other currents. A peculiar voltage dependency of $\tau_{\text {slow }}$ could be easily explained if $I_{\text {Adepol }}$ is contaminated especially at depolarized potentials.

\section{Recovery from inactivation of $\mathrm{I}_{\text {Adepol }}$}

Recovery from inactivation was examined by separating two $200 \mathrm{msec}$ pulses to $0 \mathrm{mV}$ by a variable interpulse interval at $-50 \mathrm{mV}$. The holding potential was also set to $-50 \mathrm{mV}$ in this experiment. The peak $I_{\text {Adepot }}$ in response to a second pulse was normalized to the one in response to a first pulse, and the normalized current was plotted against the interpulse interval (Fig. $8 C$ ). Recovery time course at $-50 \mathrm{mV}$ was well described by a double exponential function. The two time constants were, respectively, $0.65 \pm 0.16 \mathrm{sec}$ and $20.1 \pm 3.9 \mathrm{sec}$ in $\mathrm{R} 15(n=3)$ and $1.02 \pm 0.2 \mathrm{sec}$ and $20.4 \pm 2.1 \mathrm{sec}$ in R2 $(n=3)$. Most of the $I_{\text {Adepol }}$ (about $80 \%$ ) recovered within 2-3 sec, but full recovery required more than 1 min. To ensure full recovery, every individual trial was separated by more than $2 \mathrm{~min}$. Owing to slow recovery as well as the existence of $I_{\text {Alast }}$, the recovery at other potentials was not examined. 

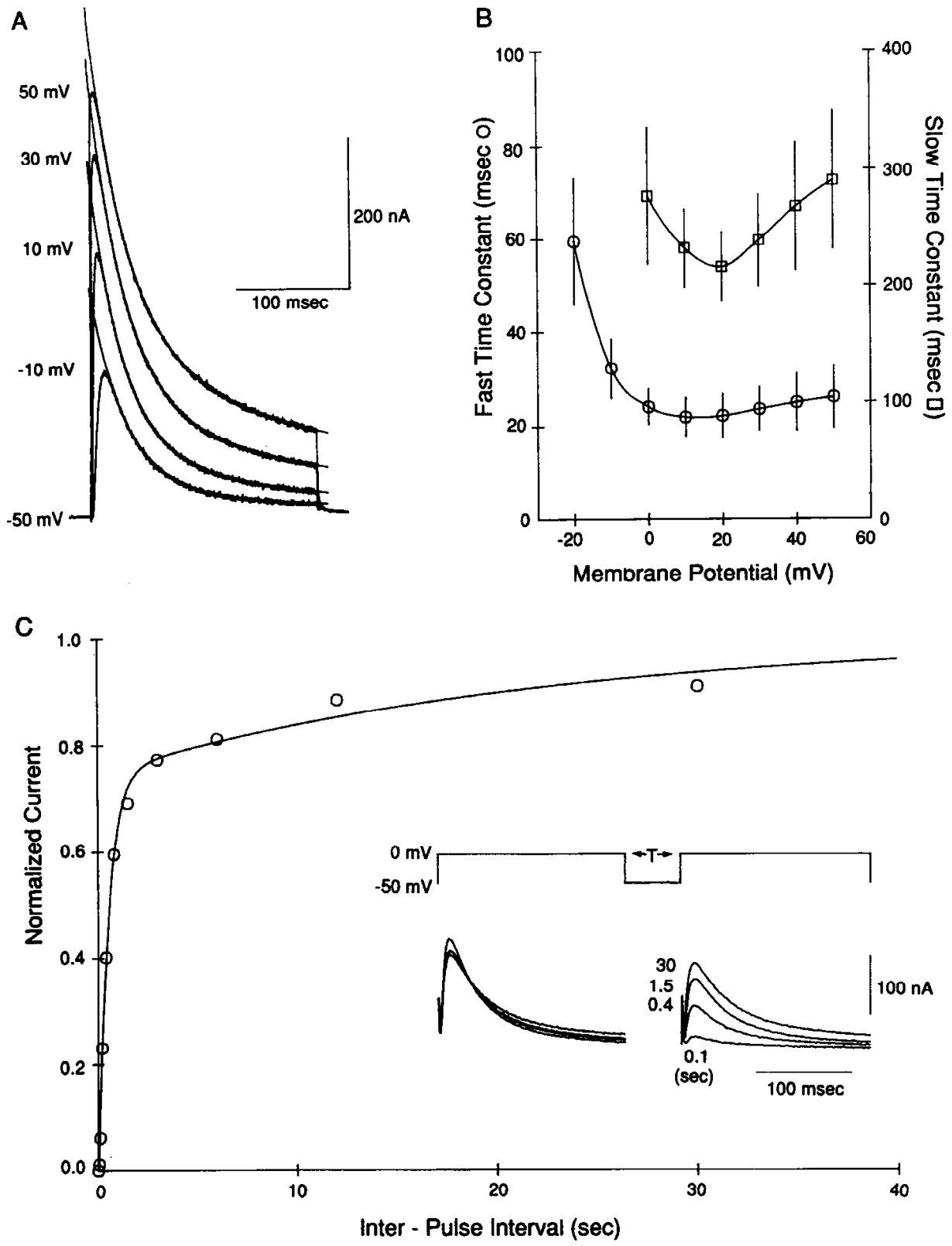

Figure 8. Inactivation of $I_{\text {Adepol }} A$, $I_{\text {Adepo }}$ of R15 in responsc to depolarizing steps to indicated voltages. $I_{\text {Adepol }}$ was isolated as described in Figure 7. Smooth lines imposed on each current trace are double exponentials. The time constants ( $\tau_{\text {fast }}$ and $\tau_{\text {slow }}$ ) are, respectively, as follows (in msec): 30.2 and 210.2 $(-10 \mathrm{mV}) ; 27.3$ and $179.8(10 \mathrm{mV})$; 30.3 and $250.5(30 \mathrm{mV}) ; 32.7$ and 305.8 $(50 \mathrm{mV}) . \quad B, \tau_{\text {fast }}$ (circles) and $\tau_{\text {slow }}$ (squares) plotted against membrane potential. Each point is a mean of four to six experiments, and bars indicate SD. $\tau_{\text {slow }}$ at $-10 \mathrm{mV}$ is not shown because at this potential current decay was well described by a single exponential in most experiments. At $-20 \mathrm{mV}$, current decay was always fit adequately by a single exponential. $C$, Recovery from inactivation. Two tandem pulses of $200 \mathrm{msec}$ to $0 \mathrm{mV}$ were applied with variable interpulse intervals. Holding potential was $-50 \mathrm{mV}$. Every trial was separated at least $2 \mathrm{~min}$. No subtraction was performed in this experiment. Thus, the current level in response to a second pulse with the shortest interval (1 msec) was assigned to 0 to measure $I_{\text {Adepol }}$. $I_{\text {Adepol }}$ at a second pulse was normalized to $I_{\text {Adepol }}$ at a first pulse, and the normalized current was plotted against the interpulse interval. The smooth line is a double exponential having two time constants of 0.523 and $22.3 \mathrm{sec}$. The inset shows the actual currents obtained with intervals as indicated. Cell, R15.

\section{Effects of 4-AP and forskolin on the three A-type $K^{+}$currents}

To obtain a pharmacological characterization of the three A-type $\mathrm{K}^{+}$currents, we examined the effects of 4-AP and forskolin. 4-AP at $5 \mathrm{~mm}$ depressed about $40-60 \%$ of the peak $I_{\text {Afast }}$ and $I_{\text {Aslow }}(n=2)$. The depression produced by 4-AP in $I_{\text {Afast }}$ and $I_{\text {Aslow }}$ was increased when the membrane was kept hyperpolarized for a long period of time before applying the test pulse. The faster component of the decay of $I_{\text {Afast }}$ became slightly more rapid, and the time to peak was also slightly decreased (Fig. $9 A 1$ ). In the presence of 4-AP, $I_{\text {Aslow }}$ decayed more slowly (Fig. $9 A 2$ ), and in some cases the current at the end of the pulse was increased. By contrast, $I_{\text {Adepol }}$ was almost completely blocked by $1 \mathrm{~mm}$ 4-AP (Fig. 9A3; $n=6$ ). At this concentration, either $I_{\text {Afast }}$ or $I_{\text {Aslow }}$ was not depressed at all.

Forskolin is a well known activator of adenylate cyclase, but there are reports that cxternally applied forskolin can depress A-type $\mathrm{K}^{+}$currents independent of an increase in intracellular c $\Lambda$ MP (Coombs and Thompson, 1987; Harris-Warrick, 1989; Baxter and Byrne, 1990). Forskolin reversibly depressed the peak of $I_{\text {Afast }}$ by about $25 \%$ (Fig. $9 B 1 ; n=3$ ). The slowly decaying current at the end of the pulse was not affected by forskolin, suggesting that this current is different from $I_{\text {Afast }}$. Forskolin decreased the peak $I_{\text {Aslow }}$ by about $35 \%$ and made the decay of the current double exponential (Fig. $9 B 2 ; n=3$ ). The decay time constant of $I_{\text {Aslow }}$ at $-15 \mathrm{mV}$ was $77.1 \pm 21.5 \mathrm{mscc}$ in control, while $I_{\text {Aslow }}$ decayed with fast and slow time constants of $10.4 \pm 1.4$ and $386 \pm 102.1 \mathrm{msec}$, respectively, in the presence of forskolin. Forskolin changed the decay time constants to the extent that the current late in the pulse was increased rather than decreased. Forskolin depressed about $60 \%$ of the peak of $I_{\text {Adepol }}$ and made the initial decay of the current faster $(n=2)$. In the experiment shown in Figure $9 B 3, \tau_{\text {fast }}$ in control and in forskolin were $21.4 \mathrm{msec}$ and $9.8 \mathrm{msec}$, respectively. Thus, the effect of forskolin on $I_{\text {Adepol }}$ was somewhat similar to the effect on $I_{\text {Aslow }}$. 

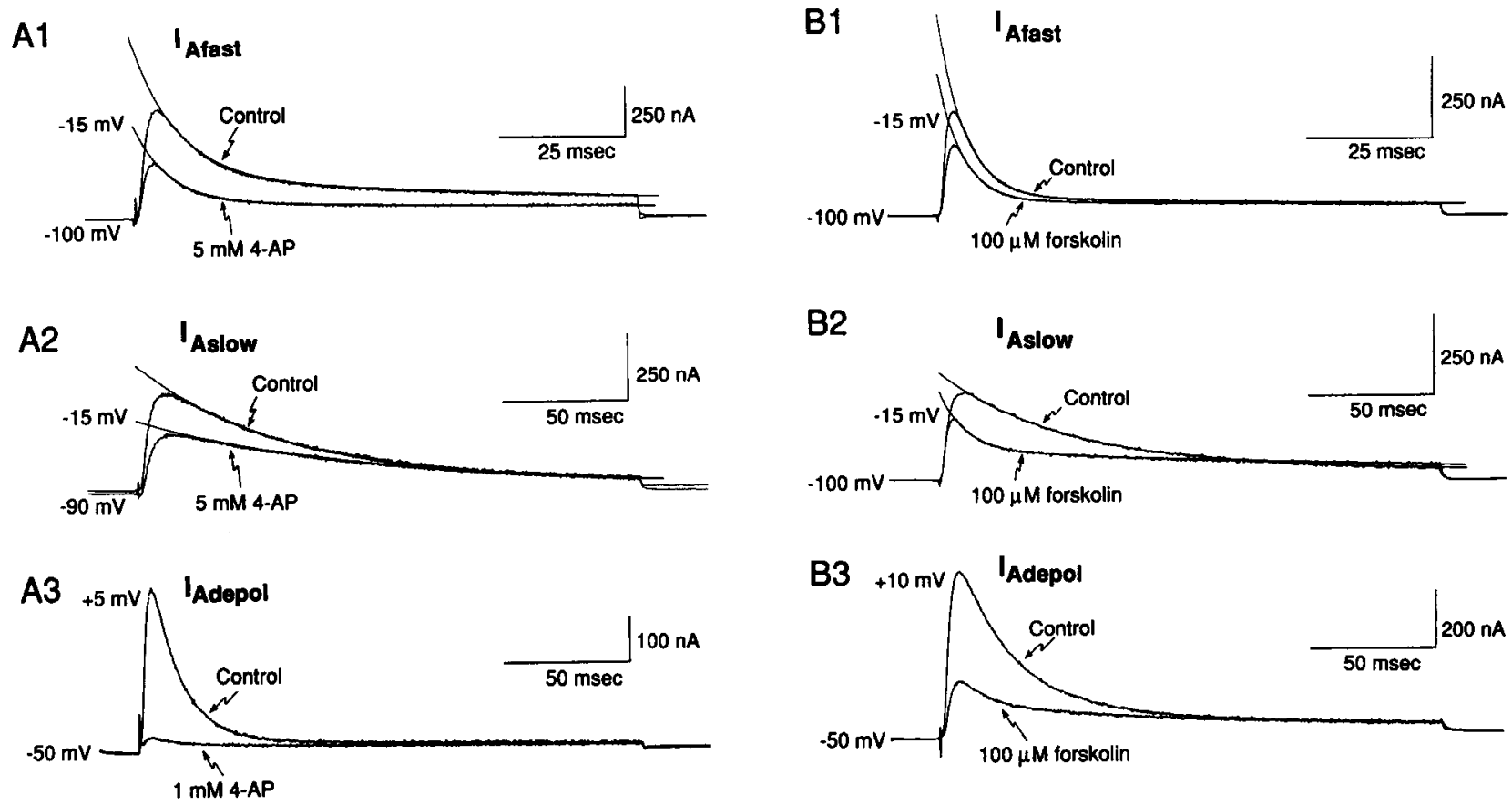

Figure 9. Effect of 4-AP $(A)$ and forskolin $(B)$ on $I_{\text {Afast }}, I_{\text {Aslow, }}$ and $I_{\text {Adepol }}$. The currents were isolated as described in Figures 2 and 7. AI, $I_{\text {Afase }}$ elicited by a $100 \mathrm{msec}$ step to $-15 \mathrm{mV}$ following a $500 \mathrm{msec}$ prepulse to $-100 \mathrm{mV}$, in the absence or the presence of $5 \mathrm{~mm} 4-\mathrm{AP}$. Imposed lines are double exponentials. Two time constants in control and in $5 \mathrm{mM} \mathrm{4-AP}$ are 9 and $161 \mathrm{msec}$ and 7.2 and $285 \mathrm{msec}$, respectively. $A 2, I_{\text {Aslow }}$ elicited by a $200 \mathrm{msec}$ step to $-15 \mathrm{mV}$ from the holding potential of $-90 \mathrm{mV}$ in the absence or the presence of 5 mM 4-AP. Imposed lines are single exponentials. The time constants in control and in $5 \mathrm{~mm} \mathrm{4-AP}$ are $58.8 \mathrm{msec}$ and $89.4 \mathrm{msec}$, respectively. $A 3, I_{\text {Adepol }}$ elicited by a $200 \mathrm{msec}$ step to $5 \mathrm{mV}$ in the absence or presence of $1 \mathrm{~mm} 4$-AP. Cell, R2. B1, $I_{\text {Afast }}$ elicited by a $100 \mathrm{msec}$ step to $-15 \mathrm{mV}$ following a $500 \mathrm{msec}$ prepulse to - 100 $\mathrm{mV}$, in the absence or the presence of $100 \mu \mathrm{M}$ forskolin. Imposed lines are double exponentials. Two time constants for inactivation in control and in $100 \mu \mathrm{M}$ forskolin are 5.3 and $225.3 \mathrm{msec}$ and 4.9 and $347.1 \mathrm{msec}$, respectively. $B 2, I_{\text {Aslow }}$ elicited by a $200 \mathrm{msec}$ step to $-15 \mathrm{mV}$ following a 1 sec prepulse to $-100 \mathrm{mV}$, in the absence or the presence of $100 \mu \mathrm{M}$ forskolin. Imposed lines are single (Control) and double (forskolin) exponentials. The time constant for inactivation in control is $51.7 \mathrm{msec}$, while the two time constants in $100 \mu \mathrm{M}$ forskolin are 11.2 and $282.5 \mathrm{msec}$. B3, $I_{\text {Adepot }}$ elicited by a $200 \mathrm{msec}$ step to $10 \mathrm{mV}$ in the absence or the presence of $100 \mu \mathrm{M}$ forskolin. Cell, R15.

The action of forskolin is not mediated by cAMP. Application of membrane-permeable cAMP analog 8(4CPT)-cAMP did not reproduce the effect of forskolin on any of these currents even at the concentration of $1 \mathrm{mM}$. Further, 1,9-dideoxy-forskolin, a forskolin analog that does not activate adenylate cyclase (Seamon and Daly, 1986), reproduced the effect of forskolin.

As described above, TEA did not block $I_{\text {Adepol }}$. Also, $I_{\text {Afast }}$ and $I_{\text {Aslow }}$ were not blocked by $50 \mathrm{~mm}$ TEA.

\section{A-type $K^{+}$currents in other identifiable neurons}

We also examined A-type $\mathrm{K}^{+}$currents in other identifiable giant neurons in Aplysia ganglia, including the metacerebral cells (MCCs), R14, L7, L11, and L14 (for nomenclature, see Frazier et al., 1967; Weiss and Kupfermann, 1976). The A-type $\mathrm{K}^{+}$ current in R14 is identical to $I_{\text {Aslow }}$, while A-type $\mathrm{K}^{+}$currents in other neurons were kinetically similar to $I_{\text {Afast }}$. The A-type $\mathrm{K}^{+}$ current in L14 has previously been examined (Byrne, 1980a,b), and its physiological importance in the cell has been described. Using our present experimental protocol, we found the kinetic properties of the A-type $\mathrm{K}^{+}$current in $\mathrm{L} 14$ to be similar to $I_{\text {Afast }}$. The presence of $I_{\text {Adepol }}$ in neurons other than R2, R15, and LUQ cells has not yet been established with certainty because the identification of $I_{\text {Adepol }}$ is more difficult in the presence of large overlapping delayed outward currents. Recently, a transient component of delayed outward currents has been reported to be sensitive to low concentrations of 4-AP in the sensory neurons of Aplysia (Baxter and Byrne, 1989). This 4-AP-sensitive transient current (Baxter and Byrne, 1989, their Fig. 3) apparently resembles $I_{\text {Adepol }}$. However, this current in the sensory neurons differs from $I_{\text {Adepol }}$ in being also blocked by 50 mM TEA (Baxter and Byrne, 1989).

\section{Discussion}

We have found three types of A-type $\mathrm{K}^{+}$currents, $I_{\text {Afast }}, I_{\text {Aslow }}$, and $I_{\text {Adepol }}$, in different identifiable cells in the Aplysia abdominal ganglion. Although the three currents differ in their kinetic properties, two of them, $I_{\text {Afast }}$ and $I_{\text {Aslow }}$, are conventional A-type $\mathrm{K}^{+}$currents by the following criteria: (1) They are transient $\mathrm{K}^{+}$currents showing a marked inactivation in response to a depolarizing step of moderate duration (Connor and Stevens, 1971a; Neher, 1971). (2) they are inactivated at $-50 \mathrm{mV}$, and the midpoints of the steady-state inactivation are around -70 $\mathrm{mV}$. These values are quite similar to those of other neuronal A-type $\mathrm{K}^{+}$currents (see Rudy, 1988, his Table 3). (3) The threshold for their activation is around $-50 \mathrm{mV}$, which is also comparable to other A-type $\mathrm{K}^{+}$currents (Rudy, 1988). (4) They are more sensitive to 4-AP than TEA (Thompson, 1977). In contrast to these two currents, the third current, $I_{\text {Adepol }}$, is a novel current that differs from conventional A-type $\mathrm{K}^{+}$currents because of its more depolarized activation and inactivation gating. We first discuss the properties of $I_{\text {Afast }}$ and $I_{\text {Aslow }}$ and then compare them with the characteristics of $I_{\text {Adepol}}$.

The time constant for the inactivation of $I_{\text {Aslow }}$ obtained from 
the rate of current decay was about $50-60 \mathrm{msec}$. In the voltage range examined (from -35 to $-15 \mathrm{mV}$ ) it was relatively voltage independent. These features as well as the midpoint of the steadystate inactivation curve are similar to previously reported A-type $\mathrm{K}^{+}$currents in some molluscan nerve cells (Connor and Stevens, 1971a; Thompson, 1977), the leech Retzius cell (Johansen and Kleinhaus, 1986), and Drosophila neurons (Solc et al., 1987).

By contrast, the decaying time constant of $I_{\text {Afast }}$ was voltage dependent, and much faster $(20-5 \mathrm{msec})$. A-type $\mathrm{K}^{+}$currents with voltage-dependent decaying time constants have been reported in Helix neurons (Neher, 1971), rat dorsal root ganglion neurons (Kostyuk et al., 1981), rat sympathetic neurons (Belluzzi et al., 1985), and rat cerebellar granule neurons (CullCandy et al., 1989).

The time constant for the inactivation of $I_{\text {Aslow }}$ obtained from the double-pulse protocol is a bell-shaped function of voltage, having its peak value around $-70 \mathrm{mV}$ (Fig. $5 B I$ ). Both the onset of the inactivation and the recovery have similar time constants at $-70 \mathrm{mV}$, a potential close to the midpoint of the steady-state inactivation curve. Further, the steady-state inactivation estimate from these experiments coincided well with the one measured directly by the conventional method (Fig. $5 B 2$ ). These results are similar to those of some A-type $\mathrm{K}^{+}$ currents described previously (Neher, 1971; Hagiwara et al., 1981; Belluzzi et al., 1985) and resemble inactivation of $\mathrm{Na}^{+}$ channels of the squid giant axons described by Hodgkin and Huxley (1952).

In the case of $I_{\text {Arast }}$, the time constants at $-70 \mathrm{mV}$ obtained by the onset of the inactivation were less than half those obtained by the recovery from the inactivation. The values of the steadystate inactivation estimated by the fitting of the recovery data were smaller than the measured one, while the values estimated from the onset data were larger (Fig. 5A2). These results may be explained if $I_{\text {Afast }}$ has an additional slower component of inactivation that can be attained during a sufficiently long depolarization. Such a component may be missed in our measurement of the onset of the inactivation because of the limited length of the conditioning pulse (usually less than $200 \mathrm{msec}$ ), resulting in an underestimate of the steady-state inactivation. On the contrary, such slow inactivation should affect the recovery from inactivation because by holding the membrane potential at $-50 \mathrm{mV}$ the channels would be recovering from the slower inactivated state. This would result in an overestimate of the steady-state inactivation, compared to experiments using inactivating prepulses of a limited duration. Such slow inactivation of $I_{\text {Afast }}$ may contribute partly to a slowly decaying current seen in Figure $2 A 3$, although we think it is more likely that this slowly decaying current is another independent current as discussed above in Results. The existence of a slower inactivation has been demonstrated for $\mathrm{Na}^{+}$channels in nerve (Rudy, 1978) and atrial myocytes (Follmer et al., 1987), and for T-type $\mathrm{Ca}^{2+}$ channels in cardiac Purkinje cells (Hirano et al., 1989). In spite of these differences, the steady-state gating properties of $I_{\text {Afast }}$ and $I_{\text {Aslow }}$ were quite similar (Fig. $2 C$; cf. Serrano and Getting, 1989).

$I_{\text {Adepol }}$ characterized in R2 and R15 also is an early transient $\mathrm{K}^{+}$current, but it has more depolarized activation and inactivation gating than conventional A-type $\mathrm{K}^{+}$currents. Thus, $I_{\text {Adepol }}$ could be separated clearly from $I_{\text {Afast }}$ by using a prepulse to -50 $\mathrm{mV}$ to inactivate $I_{\text {Afast }}$. The decay of $I_{\text {Adepol }}$, in response to a depolarizing step, can be adequately described by double exponential. Most of $I_{\text {Adepol }}(>80 \%)$ inactivates with the faster time constant, which is almost voltage independent, being more comparable to the result in $I_{\text {Aslow }}$ than in $I_{\text {Afast }}$. The slow-decaying component of $I_{\text {Adepol }}$ may relate to the slower recovery from inactivation observed in the two-pulse experiments (Fig. 8C), although the slow component of $I_{\text {Adepol }}$, especially at depolarized potentials, may be contaminated as mentioned in Results.

Another feature of $I_{\text {Adepol }}$ that is different from $I_{\text {Afast }}$ and $I_{\text {Aslow }}$ is its very slow recovery from inactivation. At $-50 \mathrm{mV}, I_{\text {Ademol }}$ inactivated by a $200 \mathrm{msec}$ pulse to $0 \mathrm{mV}$ was not fully recovered until the pulse interval was lengthened to more than $1 \mathrm{~min}$. As described in Results, $I_{\text {Adepol }}$ could be observed reliably only if hyperpolarized holding potentials $(-80 \mathrm{mV})$ were used with long pulse intervals $(20 \mathrm{sec})$. On the contrary, a $500 \mathrm{msec}$ prepulse to $-100 \mathrm{mV}$ was quite enough to remove the complete inactivation of both $I_{\text {Afast }}$ and $I_{\text {Aslow }}$ obtained at the holding potential of $-50 \mathrm{mV}$. The reason $I_{\text {Adepol }}$ was not previously described may be largely due to this slow recovery from inactivation and its overlap with delayed outward currents.

The actions of two well known $\mathrm{K}^{+}$channel blockers, TEA and 4-AP, on $I_{\text {Afasi }}, I_{\text {Aslow }}$, and $I_{\text {Adepol }}$ were similar to those previously described for other A-type $\mathrm{K}^{+}$currents: the currents were more sensitive to 4-AP than to TEA (Thompson, 1982). Although 10 mM or greater 4-AP was required to block either $I_{\text {Afast }}$ or $I_{\text {Aslow }}$ completely, $I_{\text {Adepol }}$ was almost completely blocked by $1 \mathrm{~mm}$ 4-AP. Actually, $I_{\text {Adepol }}$ appears to be the membrane current in Aplysia neurons most sensitive to 4-AP.

Forskolin depressed $I_{\text {Afast }}$ without changing the wave form of the current, suggesting that forskolin reduces the number of available channcls. In the casc of $I_{\text {Aslow }}$, the current activatcd normally until a point and then decayed more quickly in the presence of forskolin, implying an open-channel block by forskolin. In addition to this, forskolin induced another much slower decay, causing a crossover of the current traces (see Fig. 9B2). One possible explanation for this effect is that forskolin must leave the open channel before it can inactivate. Similar results have been reported in other A-type $\mathrm{K}^{+}$currents that have kinetic and voltage-dependent properties similar to $I_{\text {Aslow }}$ (Coombs and Thompson, 1987; Harris-Warrick, 1989). Thus, forskolin may become a tool to discriminate this class of A-type $\mathrm{K}^{+}$channels. The effect of forskolin on $I_{\text {Adepol }}$ was more similar to its action on $I_{\text {Aslow, }}$, although the resulting change of $I_{\text {Adepol }}$ decay was less striking. The effects of forskolin on $I_{\text {Afass }}, I_{\text {Aslow }}$, and $I_{\text {Adepol }}$ were not reproduced by $8(4 \mathrm{CPT})$-cAMP, suggesting that forskolin acts directly on these $\mathrm{K}^{+}$channels (Coombs and Thompson, 1987; Watanabe and Gola, 1987; Hoshi ct al., 1988; HarrisWarrick, 1989; Baxter and Byrne, 1990).

The present results suggest the existence of three subtypes of A-type $\mathrm{K}^{+}$channels in the Aplysia CNS. To obtain further information concerning structural and functional differences among these three A-type $\mathrm{K}^{+}$channels, we are carrying out molecular cloning of $\mathrm{K}^{+}$channels and are studying their expression in the adult nervous system of Aplysia. A cDNA encoding a Shaker homolog of Aplysia (AK01a) has recently been cloned, and a transient $\mathrm{K}^{+}$current $\left(I_{\mathrm{AKOa}}\right)$ has been observed following the injection of the synthesized cRNA in Xenopus oocytes (Pfaffinger et al., 1991). The native Aplysia $\mathrm{K}^{+}$current most similar to $I_{\text {AK012 }}$ is $I_{\text {Adepol }}$ (Pfaffinger et al., 1991). Moreover, the injection of the plasmid DNA containing the AK01a sequence into Aplysia neurons produced a transient $\mathrm{K}^{+}$current that was very similar to $I_{\text {Adepol }}$ (Kaang et al., in press). Thus, by extending these several strategies, it may become possible to elucidate molecular relationships among transient $\mathrm{K}^{+}$channels and determine the 
differential physiological roles of these $\mathrm{K}^{+}$channels in the Aplysia nervous system.

\section{References}

Baker K, Salkoff L (1990) The Drosophila Shaker gene codes for a distinctive $\mathrm{K}^{+}$current in a subset of neurons. Neuron 2:129-140.

Baxter DA, Byrne JH (1989) Serotonergic modulation of two potassium currents in the pleural sensory neurons of Aplysia. J Neurophysiol 62:665-679.

Baxter DA, Byrne JH (1990) Reduction of voltage-activated K+ currents by forskolin is not mediated via cAMP in pleural sensory neurons of Aplysia. J Neurophysiol 64:1474-1483.

Belluzzi O, Sacchi O, Wanke E (1985) A fast transient outward current in the rat sympathetic neurone studied under voltage-clamp conditions. J Physiol (Lond) 358:91-108.

Byrne JH (1980a) Analysis of ionic conductance mechanisms in motor cells mediating inking behavior in Aplysia californica. J Neurophysiol 43:630-650.

Byrne JH (1980b) Quantitative aspects of contributing ionic conductance mechanisms contributing to firing pattern of motor cells mediating inking behavior in Aplysia californica. J Neurophysiol 43: 651-668.

Connor JA, Stevens CF (1971a) Voltage clamp studies of a transient outward membrane current in gastropod neural somata. J Physiol (Lond) 213:21-30.

Connor JA, Stevens CF (1971b) Prediction of repetitive firing behaviour from voltage clamp data on an isolated neurone soma. J Physiol (Lond) 213:31-53.

Coombs J, Thompson S (1987) Forskolin's effect on transient K current in nudibranch neuron is not reproduced by cAMP. J Neurosci $7: 443-452$.

Cull-Candy SG, Marshall CG, Ogden D (1989) Voltage-activated membrane currents in rat cerebellar granule neurones. J Physiol (Lond) 414:179-199.

Follmer CH, Ten Eick RE, Yeh JZ (1987) Sodium current kinetics in cat atrial myocytes. J Physiol (Lond) 384:169-197.

Frazier WT, Kandel ER, Kupfermann I, Waziri R, Coggeshall RE (1967) Morphological and functional properties in identified neurons in the abdominal ganglion of Aplysia californica. J Neurophysiol 30:12881351.

Hagiwara S, Yoshida S, Yoshii M (1981) Transient and delayed potassium currents in the egg cell membrane of the coelenterate, Renilla koellikeri. J Physiol (Lond) 318:123-141.

Harris-Warrick RM (1989) Forskolin reduces a transient potassium current in lobster neurons by a cAMP-independent mechanism. Brain Res 489:59-66.

Hermann A, Gorman ALF (1981) Effects of tetraethylammonium on potassium currents in a molluscan neuron. J Gen Physiol 78:87-110.

Hirano Y, Fozzard HA, January CT (1989) Inactivation properties of T-type calcium current in canine cardiac Purkinje cells. Biophys J 56: 1007-1016.

Hodgkin AL, Huxley AF (1952) The dual effect of membrane potential on sodium conductance in the giant axon of Loligo. J Physiol (Lond) 116:497-506.

Hoshi T, Garber SS, Aldrich RW (1988) Effect of forskolin on voltagegated $\mathrm{K}^{+}$channels is independent of adenylate cyclase activation. Science 240:1652-1655.
Iverson LE, Tanouye MA, Lester HA, Davidson N, Rudy B (1988) A-type potassium channels expressed from Shaker locus cDNA. Proc Natl Acad Sci USA 85:5723-5727.

Jan YN, Jan LY, Dennis MJ (1977) Two mutations of synaptic transmission in Drosophila. Proc R Soc Lond [Biol] 198:87-108.

Johansen J, Kleinhaus AL (1986) Transient and delayed potassium currents in the Retzius cell of the leech, Macrobdella decora. J Neurophysiol 56:812-822.

Kostyuk PG, Veselovsky NS, Fedulova SA, Tsyndrenko AY (1981) Ionic currents in the somatic membrane of rat dorsal root ganglion neurons. III. Potassium currents. Neuroscience 6:2439-2444.

Neher E (1971) Two fast transient current components during voltage clamp on snail neurons. J Gen Physiol 58:36-53.

Pfaffinger PJ, Furukawa Y, Zhao B, Dugan D, Kandel ER (1991) Cloning and expression of an Aplysia $\mathrm{K}^{+}$channel and comparison with native Aplysia $\mathrm{K}^{+}$currents. J Neurosci 11:918-927.

Premack BA, Thompson S, Coombs-Hahn J (1989) Clustered distribution and variability in kinetics of transient $\mathrm{K}$ channels in molluscan neuron cell bodies. J Neurosci 9:4089-4099.

Rogawski MA (1985) The A-current: how ubiquitous a feature of excitable cells is it? Trends Neurosci 8:214-219.

Rudy B (1978) Slow inactivation of the sodium conductance in squid giant axons. Pronase resistance. J Physiol (Lond) 283:1-21.

Rudy B (1988) Diversity and ubiquity of $K$ channels. Neuroscience 25:729-749.

Salkoff LB, Wyman RJ (1981) Genetic modification of potassium channels in Drosophila Shaker mutants. Nature 293:228-230.

Seamon KB, Daly JW (1986) Forskolin: its biological and chemical properties. Adv Cyclic Nucleotide Protein Phosphorylation Res 20: $1-150$.

Serrano EE, Getting PA (1989) Diversity of the transient outward potassium current in somata of identified molluscan neurons. J Neurosci 9:4021-4032.

Shimahara T (1983) Presynaptic modulation of transmitter release by the early outward potassium current in Aplysia. Brain Res 263:5156.

Solc CK, Zagotta WN, Aldrich RW (1987) Single-channel and genetic analyses reveal two distinct A-type potassium channels in Drosophila. Science 236:1094-1098.

Tanouye MA, Ferrus A, Fujita SC (1981) Abnormal action potentials associated with the Shaker complex locus of Drosophila. Proc Natl Acad Sci USA 78:6548-6552.

Thompson SH (1977) Three pharmacologically distinct potassium channels in molluscan neurones. J Physiol (Lond) 265:465-488.

Thompson SH (1982) Aminopyridine block of transient potassium current. J Gen Physiol 80:1-18.

Timpe LC, Schwarz TL, Tempel BL, Papazian DM, Jan YN, Jan LY (1988) Expression of functional potassium channels form Shaker cDNA in Xenopus oocytes. Nature 331:143-145.

Watanabe K, Gola M (1987) Forskolin interaction with voltage-dependent $\mathrm{K}$ channels in Helix is not mediated by cyclic nucleotides. Neurosci Lett 78:211-216.

Weiss KR, Kupfermann I (1976) Homology of the giant serotonergic neurons (metacerebral cells) in Aplysia and pulmonate molluscs. Brain Res 117:33-49.

Zhao B, Kandel ER (1991) Molecular cloning of a new $\mathrm{K}^{+}$channel in Aplysia. Soc Neurosci Abstr 17:1281. 